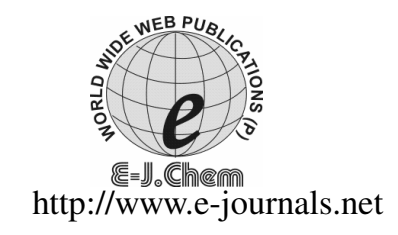

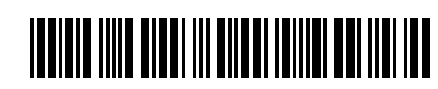

ISSN: 0973-4945; CODEN ECJHAO

E-Journal of Chemistry 2011, 8(3), 992-999

\title{
Effect of Heat Treatment on the Surface Properties of Activated Carbons
}

\author{
MERIEM BELHACHEMI ${ }^{*}$ and FATIMA ADDOUN \\ *Faculté Des Sciences ET Technologie \\ Université De BECHAR, B.P 417, 08000-Béchar, Algeria \\ Laboratoire D'étude Physico Chimique Des Matériaux ET Application à L'environnement \\ Faculté de Chimie, USTHB, B.P.32, El Alia 16111-Bab Ezzouar Alger, Algeria \\ bel_meriem@yahoo.fr
}

Received 7 July 2010; Accepted 3 October 2010

\begin{abstract}
This work reports the effect of heat treatment on the porosity and surface chemistry of two series of activated carbons prepared from a local agricultural biomass material, date pits, by physical activation with carbon dioxide and steam. Both series samples were oxidized with nitric acid and subsequently heat treated under $\mathrm{N}_{2}$ at $973 \mathrm{~K}$ in order to study the effect of these treatments in porosity and surface functional groups of activated carbons. When the activated carbons were heat treated after oxidation the surface area and the pore volume increase for both activated carbons prepared by $\mathrm{CO}_{2}$ and steam activations. However the amount of surface oxygen complexes decreases, the samples keep the most stable oxygen surface groups evolved as $\mathrm{CO}$ by temperature-programmed desorption experiments at high temperature. The results show that date pits can be used as precursors to produce activated carbons with a well developed porosity and tailored oxygen surface groups.
\end{abstract}

Keywords: Activated carbon, Heat treatment, Porosity, Surface oxygen complexes

\section{Introduction}

Carbon materials are finding an increasing number of applications in industrial wastewater, in gas treatment, in catalysis, either as supports for the active phases, or as catalysts on their own. Their performance is determined both by their texture and surface chemistry ${ }^{1,2}$.

In the case of activated carbons, the texture may be adapted to suit the situation by adequate choice of the activation procedure. On the other hand, the nature and concentration of surface functional groups may be modified by suitable chemical or thermal posttreatments. Oxidation in the gas or liquid phase can be used to increase the concentration of surface oxygen groups, while heating under inert atmosphere may be used to selectively remove some of these functions. Carboxyl, carbonyl, phenol, quinone and lactone groups, have been identified on carbon surfaces ${ }^{3,4}$. 
Two series of activated carbons with high porosity were prepared from date pits using $\mathrm{CO}_{2}$ and steam activations method. The oxidized-AC and heat treated-AC samples were prepared by acidic oxidization and heat treatment at $700{ }^{\circ} \mathrm{C}$, respectively. The objective of this work is to make analysis of the effect caused by the oxidation and heat treatments in the development of porous structure and surface chemistry of both series of activated carbons prepared with different degrees of activation.

\section{Experimental}

The two series of activated carbons were prepared from a common char, prepared by the carbonization of date pits (nitrogen flow of $150 \mathrm{~mL} / \mathrm{min} ; 1098 \mathrm{~K}$; heating rate, $5 \mathrm{~K} / \mathrm{min}$; residence time 2 hours). A common horizontal furnace was used for the different activation processes, defined as follows:

- Series C: the char was activated with $\mathrm{CO}_{2}(150 \mathrm{~mL} / \mathrm{min})$ at $1073 \mathrm{~K}$ using different periods of time, i.e. $120,180,270,460$ and $560 \mathrm{~min}$, which correspond to burn-off of $16,28,37,50$ and $64 \%$ respectively.

- Series S: the char was submitted to physical activation with steam $(150 \mathrm{~mL} / \mathrm{min})$ at $1073 \mathrm{~K}$ using different periods of time, i.e. 45, 75 and $120 \mathrm{~min}$, which correspond to burn-off of 11,34 and $49 \%$ respectively.

Further experimental details can be found in reference. ${ }^{5}$. The nomenclature of all activated carbons includes the letter for the series and the burn-off reached. In order to study the effect of surface functional groups in the texture and the nature of activated carbons. The samples of series $\mathrm{C}$ and series $\mathrm{S}$ were treated with concentrated $\mathrm{HNO}_{3}(14 \mathrm{M})$ at boiling temperature for $10 \mathrm{~min}$. Then, they were washed with distilled water and dried at $378 \mathrm{~K}$. The prepared activated carbons are respectively named as $\mathrm{C}$ (burn-off)N and $\mathrm{S}$ (burn-off)N. Subsequently the thermal treatment was performed on a fraction of oxidized samples under a $\mathrm{N}_{2}$ flow with a heating rate of $10 \mathrm{~K} / \mathrm{min}$ until final temperature of $973 \mathrm{~K}$ and kept at this temperature for $1 \mathrm{~h}$ in order to selectively remove some of the oxygen surface groups. The samples obtained was referred as C(burn-off)NT and S(burn-off)NT.

$\mathrm{N}_{2}$ and $\mathrm{CO}_{2}$ adsorption-desorption isotherms were obtained in a static manometric apparatus at $77 \mathrm{~K}$ and $273 \mathrm{~K}$, respectively. Before the experiment, the samples were outgassed at $423 \mathrm{~K}$ for $4 \mathrm{~h}$ under vacuum $\left(10^{-3} \mathrm{~Pa}\right)$. The "apparent" surface area was obtained using the BET method. The micropore volume $\left(\mathrm{V}_{0}\left(\mathrm{~N}_{2}\right)\right)$ was deduced from the $\mathrm{N}_{2}$ adsorption data using the Dubinin-Raduskevitch (DR) equation, while the mesopore volume $\left(\mathrm{V}_{\text {meso }}\right)$ was obtained as the difference between the total pore volume $\left(\mathrm{V}_{\mathrm{T}}\left(\mathrm{N}_{2}\right)\right)$ adsorbed at $\mathrm{p} / \mathrm{p}_{\mathrm{o}} \approx 0.95$ and the micropore volume $\left(\mathrm{V}_{0}\left(\mathrm{~N}_{2}\right)\right)$. The pore volume corresponding to the narrow microporosity $\left(\mathrm{V}_{0}\left(\mathrm{CO}_{2}\right)\right)$ was obtained after application of the DR equation to the $\mathrm{CO}_{2}$ adsorption data ${ }^{6}$.

Temperature-programmed desorption experiments under helium were carried out to evaluate the amount and nature of the oxygen surface groups present in each sample. Thus, $100 \mathrm{mg}$ of sample were placed in a U-shaped quartz reactor on-line coupled to a quadrupole mass spectrometer (Balzer MSC200). The experiments were performed up to $1273 \mathrm{~K}$ under a he flow $(50 \mathrm{~mL} / \mathrm{min})$ and a heating rate of $10 \mathrm{~K} / \mathrm{min}$. The amount of $\mathrm{CO}$ and $\mathrm{CO}_{2}$ evolved were quantified after calibration with calcium oxalate $\left(\mathrm{CaC}_{2} \mathrm{O}_{4}-\mathrm{H}_{2} \mathrm{O}\right)$.

\section{Results and Discussion}

\section{Textural change}

$\mathrm{N}_{2}$ adsorption desorption isotherms at $77 \mathrm{~K}$ for the different activated carbons are shown in Figure 1. Additionally, Table 1 reports the textural characteristics obtained from the $\mathrm{N}_{2}$ and $\mathrm{CO}_{2}$ adsorption isotherms at $77 \mathrm{~K}$ and $273 \mathrm{~K}$, respectively. It can be observed that the increase in the degree of activation brings about an increase in the porosity for both series $\mathrm{C}$ and $\mathrm{S}$. 
Figure 1a compares the nitrogen adsorption isotherms for series $\mathrm{C}$ activated carbons. It can be observed from the isotherm's shape that the activation process produces an increase in the microporous volume together with the development of wider micropores and mesopores. In fact, the C64 sample exhibits a higher BET surface area $\left(1669 \mathrm{~m}^{2} / \mathrm{g}\right)$, as well as higher micropore $\left(0,67 \mathrm{~m}^{3} / \mathrm{g}\right)$ and total $\left(0.91 \mathrm{~m}^{3} / \mathrm{g}\right)$ pore volume (Table 1$)$. These results are in correspondence with the broad knee and no plateau exhibited by the nitrogen isotherm, indicating the presence of a broad and a well developed microporous structure. In this series of activated carbons there is a continuous increase in microporosity from the starting char up to $50 \%$ burn-off (both $\mathrm{V}_{0}\left(\mathrm{CO}_{2}\right)$ and $\mathrm{V}_{0}\left(\mathrm{~N}_{2}\right)$ increase). From then on total microporosity $\left(\mathrm{V}_{0}\left(\mathrm{~N}_{2}\right)\right)$ still increases but the narrower porosity $\left(\mathrm{V}_{0}\left(\mathrm{CO}_{2}\right)\right)$ stabilizes.
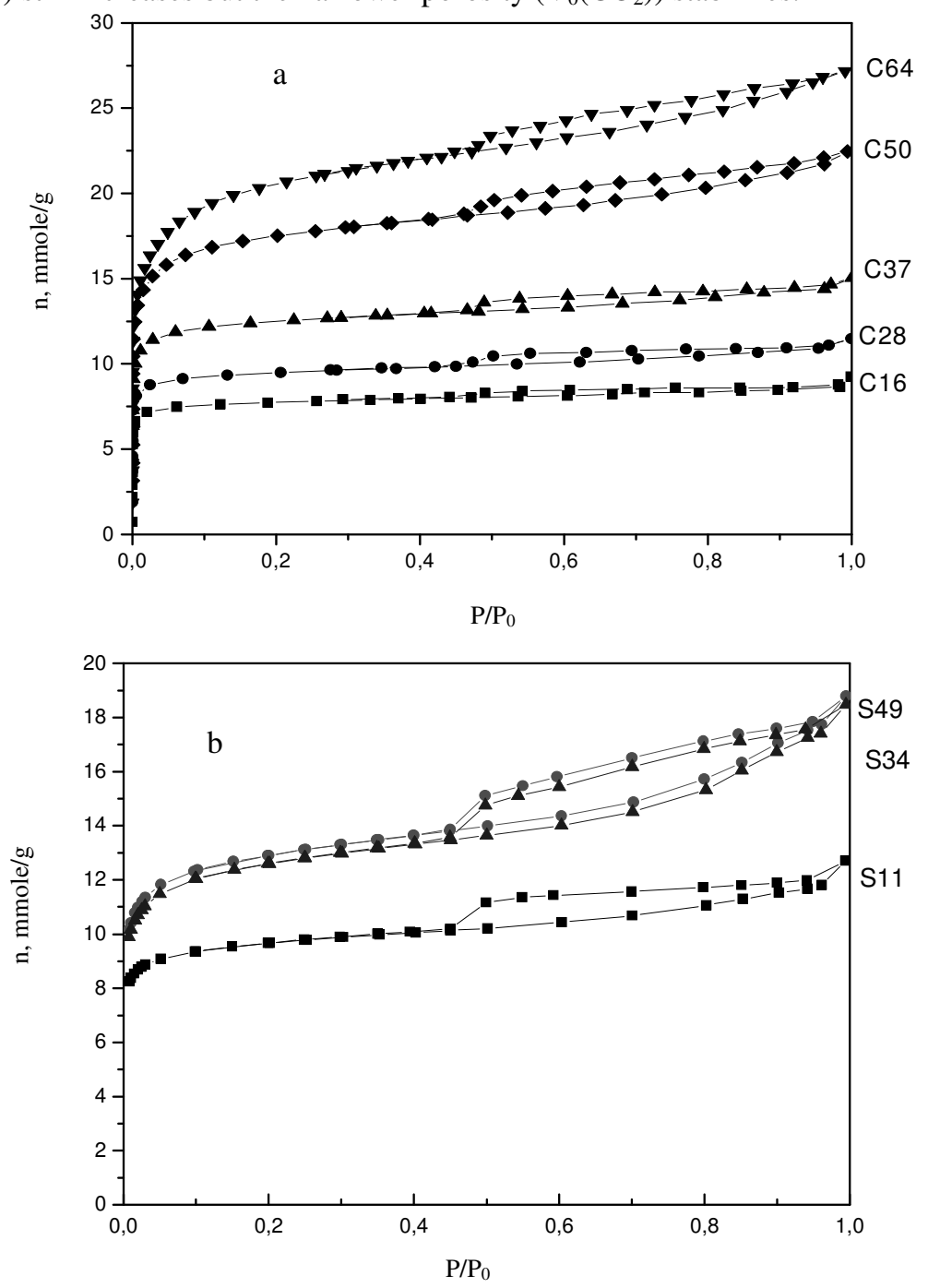

Figure 1. $\mathrm{N}_{2}$ adsorption desorption isotherms at $77 \mathrm{~K}$ for activated carbons with increasing burn-off (a) samples activated with $\mathrm{CO}_{2}$ and (b) samples activated with steam 
All adsorption isotherms of series S (Figure 1b) present an hysteresis (the desorption is not coexistent with the adsorption isotherm) from the first stage of activation, indicating the presence of mesopores.then total microporosity $\left(\mathrm{V}_{0}\left(\mathrm{~N}_{2}\right)\right)$ strongly increases from the char up to about $11 \%$ burn-off, the development being less accentuated for higher activation degrees. Narrow microporosity $\left(\mathrm{V}_{0}\left(\mathrm{CO}_{2}\right)\right)$ also increases in the initial stages (from 0.20 to $0.33 \mathrm{~cm}^{3} \mathrm{~g}^{-1}$ ), but then it remains constant as activation proceeds. This means that only widening of existing narrow micropores occurs during the rest of activation.

From these results, it clear that activation with carbon dioxide uniformly develops all the pore size ranges, as increasing activation produces a continuous increase in the volume of both micropores and mesopores, however steam is more effective in micropore widening 5 .

In order to explore the effect of oxygen surface groups in the texture of activated carbons, samples of series $\mathrm{C}$ and $\mathrm{S}$ were submitted to an oxidation treatment with $\mathrm{HNO}_{3}$ and subsequently heat treated under $\mathrm{N}_{2}$ in order to selectively remove some of the oxygen surface groups. Figure 2 includes $\mathrm{N}_{2}$ adsorption-desorption isotherms at $77 \mathrm{~K}$ for the activated carbon $\mathrm{C} 50$ and S49 before and after the oxidation treatment with $\mathrm{HNO}_{3}$, together with the isotherm after the heat treatment in $\mathrm{N}_{2}$ at $973 \mathrm{~K}$. The oxidation treatment with a strong oxidizer such as $\mathrm{HNO}_{3}$ produces some changes in the adsorption properties of both samples $\mathrm{C} 50$ and $\mathrm{S} 49$, although their microporous nature is preserved. The oxidized samples exhibit a decrease in the total adsorption capacity, in the surface area and in the pore volume (Table 1), with regard to the respective values of the original samples and the decrease in these values became more pronounced with increasing degree of activation. Previous studies on activated carbons have shown that the effect of an oxidation treatment with $\mathrm{HNO}_{3}$ highly depends on the nature of the carbon sample, the concentration of nitric acid and the extent (time) of the oxidation process ${ }^{7,8}$. In this sense, the oxidation treatment can modify only the chemical nature of the carbon surface with mainly no effect in the porosity or it can produce the collapse of small pores, thus modifying the porous structure.

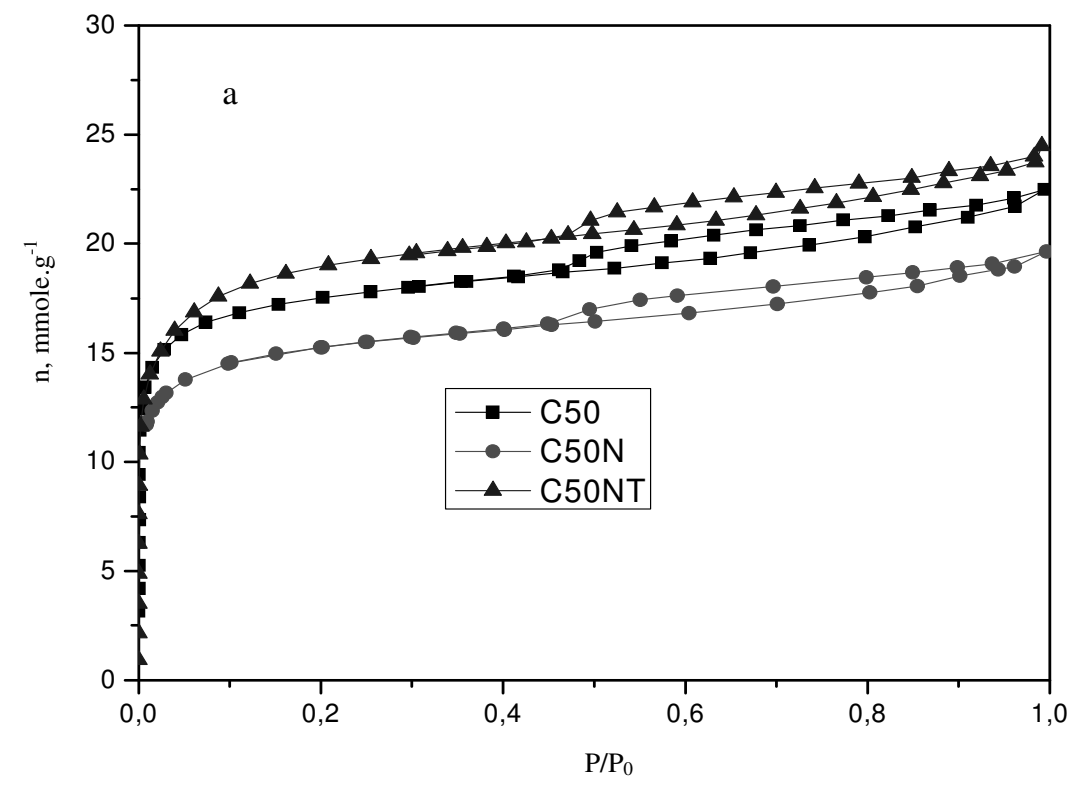




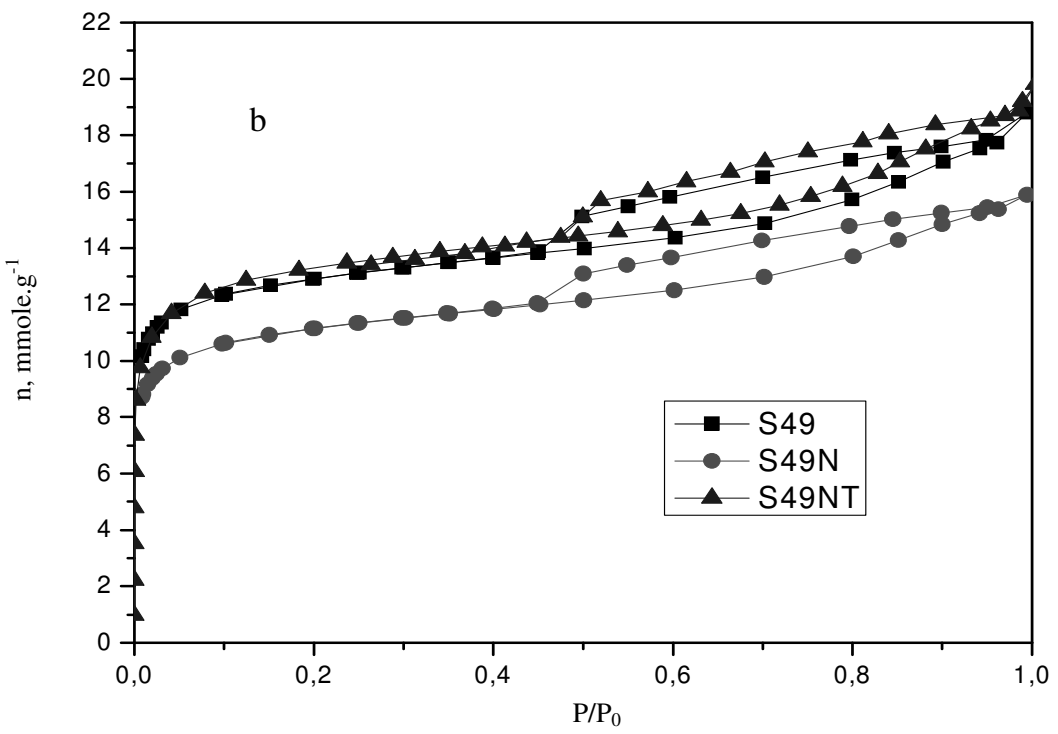

Figure 2. $\mathrm{N}_{2}$ adsorption desorption isotherms at $77 \mathrm{~K}$ for (a) C50 and (b) S49 carbons as prepared, after an oxidation treatment with $\mathrm{HNO}_{3}$ and after a subsequent thermal treatment in $\mathrm{N}_{2}$ at $973 \mathrm{~K}$

Table 1. Specific surface area and pore volume calculated from the $\mathrm{N}_{2}$ and $\mathrm{CO}_{2}$ adsorption isotherms at $77 \mathrm{~K}$ and $273 \mathrm{~K}$, respectively, for the different activated carbons after treatments

\begin{tabular}{ccccc}
\hline Sample & $\mathrm{S}_{\mathrm{BET}, \mathrm{m}} \mathrm{m}^{2} \cdot \mathrm{g}^{-1}$ & $\mathrm{~V}_{0}\left(\mathrm{~N}_{2}\right), \mathrm{cm}^{3} \cdot \mathrm{g}^{-1}$ & $\mathrm{~V}_{0.95}-\mathrm{V}_{0}\left(\mathrm{~N}_{2}\right), \mathrm{cm}^{3} \cdot \mathrm{g}^{-1}$ & $\mathrm{~V}_{0}\left(\mathrm{CO}_{2}\right), \mathrm{cm}^{3} \cdot \mathrm{g}^{-1}$ \\
\hline Char & -- & -- & & 0.20 \\
C16 & 685 & 0.27 & 0.03 & 0.27 \\
C16N & 652 & 0.25 & 0.03 & 0.27 \\
C16NT & 663 & 0.27 & 0.03 & 0.27 \\
C37 & 1069 & 0.44 & 0.08 & 0.36 \\
C37N & 950 & 0.37 & 0.05 & 0.35 \\
C37NT & 1160 & 0.46 & 0.07 & 0.39 \\
C50 & 1443 & 0.59 & 0.17 & 0.42 \\
C50N & 1256 & 0.52 & 0.13 & 0.35 \\
C50NT & 1552 & 0.59 & 0.22 & 0.39 \\
S34 & 1067 & 0.43 & 0.17 & 0.33 \\
S34N & 891 & 0.37 & 0.15 & 0.28 \\
S34NT & 1048 & 0.42 & 0.18 & 0.31 \\
S49 & 1096 & 0.44 & 0.17 & 0.35 \\
S49N & 916 & 0.38 & 0.15 & 0.28 \\
S49NT & 1111 & 0.43 & 0.21 & 0.32 \\
\hline
\end{tabular}

When the carbons are heat treated under nitrogen at $973 \mathrm{~K}$ to remove the less stable oxygen surface groups, the $\mathrm{N}_{2}$ isotherm resembles that of the original sample and the BET surface area of new carbons are even higher than that of the parent carbons for both series, $\mathrm{C}$ and $\mathrm{S}$. These results can be explained by considering the blocking effect of the oxygen surface groups in the oxidized carbons which limit the accessibility of the nitrogen molecule to the narrow micropores at the low adsorption temperature $(77 \mathrm{~K})$. A heat treatment at 
temperature $(973 \mathrm{~K})$ under nitrogen causes the removal of an important part of the oxygen surface groups (the less stable groups, evolved as $\mathrm{CO}_{2}$ in temperature-programmed experiments, together with part of the more stable and less acidic oxygen groups, which evolve as $\mathrm{CO}$ ), together with carbon atoms what, in fact, is an activation process that increases the surface area and the pore volume (mainly the mesoporosity) of carbons. The results are more pronounced for carbons prepared with $\mathrm{CO}_{2}$ activation and with high burn off.

In summary, these results show that the oxidation treatment of samples with a strong oxidizer $\left(\mathrm{HNO}_{3}\right)$ modifies the surface chemistry with mainly no effect on the porosity. The newly created oxygen surface groups located in the pore mouth of the micropores gives rise to diffusional restrictions for the $\mathrm{N}_{2}$ molecule at $77 \mathrm{~K}$. However, a subsequent heat treatment at high temperature $\left(973 \mathrm{~K}\right.$ ) with $\mathrm{N}_{2}$ is able to completely recover the adsorption properties and surface area of the original activated carbon.

\section{Change in surface chemistry}

The amount and nature of the oxygen surface groups on the different activated carbons has been analyzed by temperature-programmed desorption experiments. In this sense, Table 2 reports the total amount of oxygen surface groups evolved both as $\mathrm{CO}_{2}$ and $\mathrm{CO}$ for all activated carbons before and after treatments. According to Table 2, an increase in burn-off has mainly no effect in the total amount of oxygen surface groups evolved as $\mathrm{CO}_{2}$ (carboxylic acid, lactone, etc.), i.e. the least stable groups. However, the situation is different for the oxygen surface groups evolved as $\mathrm{CO}$, i.e. the most stable groups. The amount of $\mathrm{CO}$ increases with increasing degree of activation for both series. As the burn-off is directly related to the severity of the activation process, this could be due to the higher thermal stability of $\mathrm{CO}$ evolving groups and the lower thermal stability of the $\mathrm{CO}_{2}$ evolving groups. The amount of $\mathrm{CO}$ evolved is higher and it depends on the activating agent. This effect is clearly reflected in the $\mathrm{CO} / \mathrm{CO}_{2}$ ratio, which increases continuously with the degree of activation. However, this value is not meaningful for activated carbons of series $\mathrm{S}$ (activated with steam). Thus, the activation treatment with $\mathrm{CO}_{2}$ slightly favors the development of oxygen surface groups, mainly those evolved as CO.

Table 2. Amount of $\mathrm{CO}_{2}$ and $\mathrm{CO}$ evolved during the TPD experiments on the as-synthesized, oxidized and heat treated activated carbons

\begin{tabular}{cccc}
\hline Sample & $\mathrm{CO}, \mathrm{mmol.g}$ & $\mathrm{CO}_{2}, \mathrm{mmol}^{-1} \mathrm{~g}^{-1}$ & $\mathrm{CO} / \mathrm{CO}_{2}$ \\
\hline $\mathrm{C} 16$ & 0.89 & 0.41 & 2.1 \\
$\mathrm{C} 16 \mathrm{~N}$ & 1.5 & 0.38 & 3.9 \\
$\mathrm{C} 16 \mathrm{NT}$ & 0.82 & 0.27 & 3.0 \\
$\mathrm{C} 37$ & 1.17 & 0.43 & 2.7 \\
$\mathrm{C} 37 \mathrm{~N}$ & 2.55 & 1.05 & 2.4 \\
$\mathrm{C} 37 \mathrm{NT}$ & 0.92 & 0.14 & 6.5 \\
C50 & 1.22 & 0.39 & 3.1 \\
C50N & 2.67 & 1.04 & 2.5 \\
C50NT & 0.74 & 0.06 & 12.3 \\
S34 & 0.90 & 0.40 & 2.2 \\
S34N & 3.23 & 1.15 & 2.8 \\
S34NT & 0.59 & 0.10 & 5.9 \\
S49 & 0.95 & 0.40 & 2.3 \\
S49N & 3.53 & 1.51 & 2.3 \\
S49NT & 0.49 & 0.09 & 5.4 \\
\hline
\end{tabular}


The oxidation and thermal treatment produce important changes in the surface chemistry. Figure 3 shows the (a) $\mathrm{CO}_{2}$ and (b) $\mathrm{CO}$ desorption profiles for the different activated carbons in the 298-1273 $\mathrm{K}$ temperature range. As it can be clearly observed from this figure, carbon $\mathrm{S} 49 \mathrm{~N}$ exhibits the highest amount of oxygen surface groups, these groups being mainly evolved as $\mathrm{CO}$. The $\mathrm{CO}$ evolution profile presents a large peak at high temperatures $(973-1123 \mathrm{~K})$, which results from the decomposition of phenols, ethers and carbonyls ${ }^{7,9}$. Additionally from Table 2, the oxidized samples exhibit an important increase in the total amount of oxygen surface groups evolved both as $\mathrm{CO}_{2}$ and $\mathrm{CO}$, this enhancement being higher for the $\mathrm{CO}_{2}$ groups (lower $\mathrm{CO} / \mathrm{CO}_{2}$ ratio). The oxygen surface groups increase with increasing burn-off, which is attributed to the higher surface area and more developed porosity of the starting activated carbons with the degree of activation. Samples of series $\mathrm{S}$ were able to fix a larger amount of oxygen groups than series $\mathrm{C}$, probably because of their wider microporosity and subsequent better accessibility to the acid solution. However, the subsequent thermal treatment in $\mathrm{N}_{2}$ up to $973 \mathrm{~K}$ is more effective for the more acid groups as observed from the increase in the $\mathrm{CO} / \mathrm{CO}_{2}$ ratio in both series. On the other hand, C50NT exhibits a $\mathrm{CO}$ peak at high temperature from $1073 \mathrm{~K}$ to $1273 \mathrm{~K}$ (see Figure $3 \mathrm{a}$ ). These groups can be assigned to carbonyl, quinone, pyrone and chromene type structures which have basic properties. Thermally treated samples have a basic character which is due to this kind of oxygen-containing groups and mainly to the electron rich oxygen-free sites located on the carbon basal planes ${ }^{11}$. However the amount of $\mathrm{CO}_{2}$ evolved is almost nil for both samples (C50NT and S49NT); the sample C50NT presents the highest $\mathrm{CO} / \mathrm{CO}_{2}$ ratio. As a result, the activated carbons prepared with carbon dioxide with high degree of activation present the most stable groups, as it was already noted in the parent activated carbons.

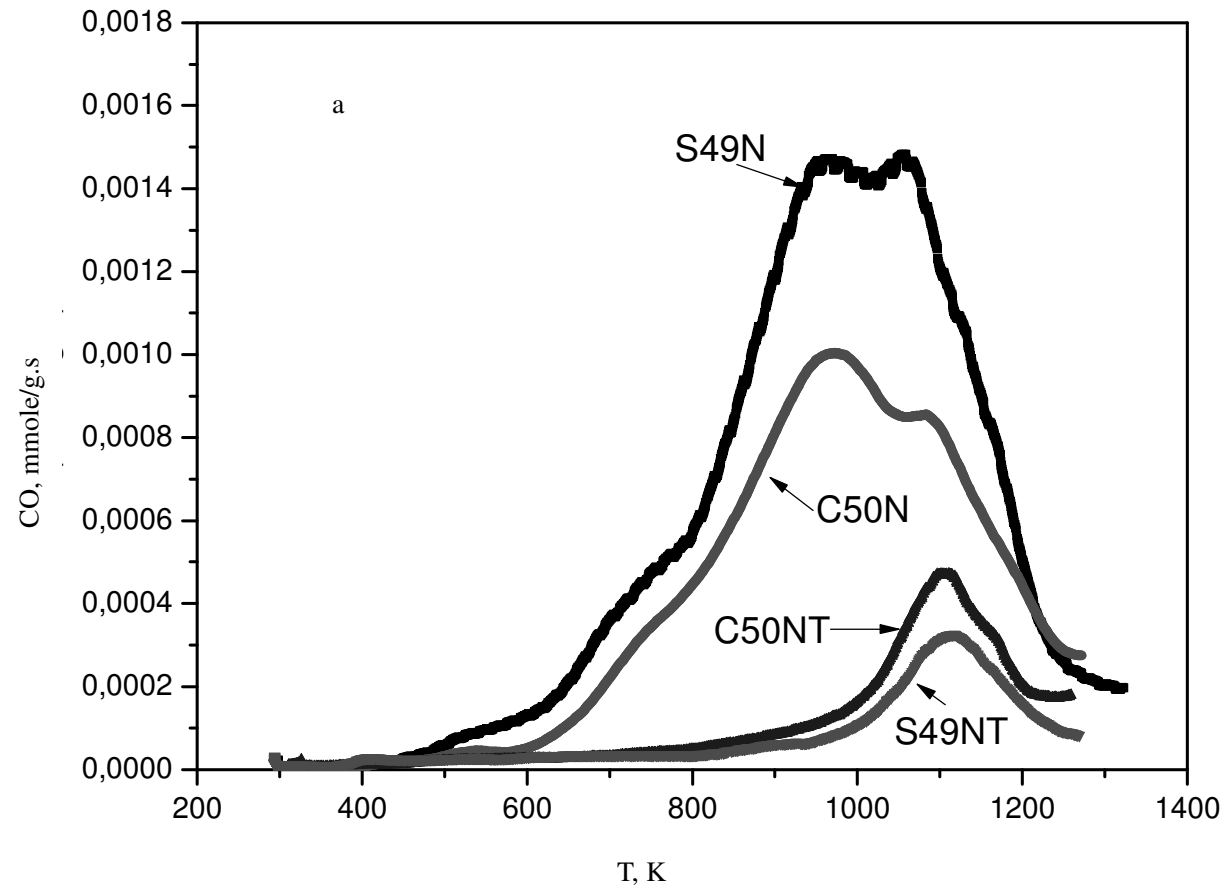




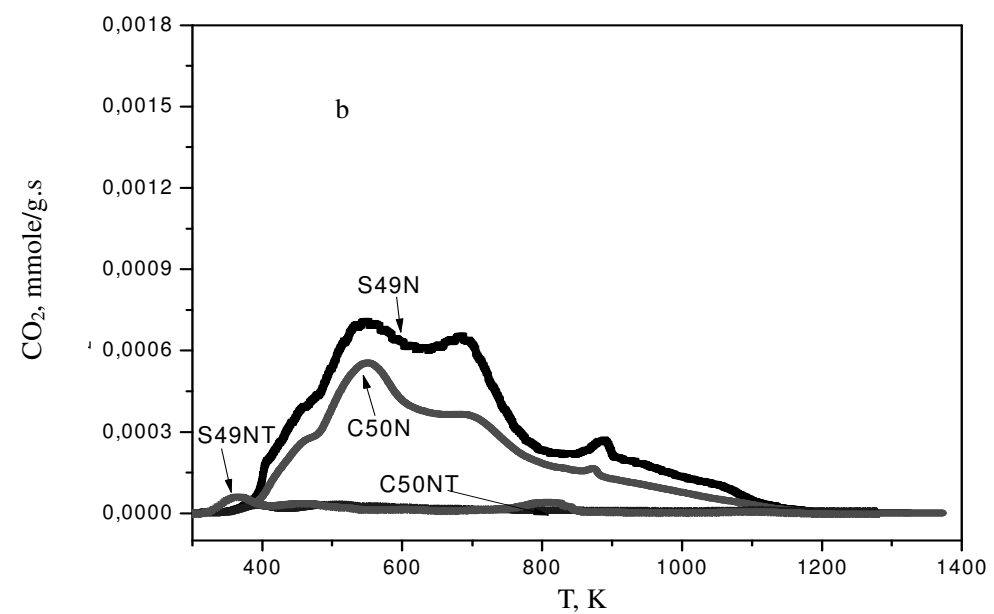

Figure 3. Evolution profiles of $\mathrm{CO}$ and $\mathrm{CO}_{2}$ in TPD experiments for oxidized (C50N and $\mathrm{S} 49 \mathrm{~N})$ and heat treated (C50NT and S49NT) carbons

\section{Conclusion}

Oxidation with nitric acid produces a slight decrease of the porosity and the surface area of activated carbon, although drastic changes in the chemical nature of the surface take place. Heat treatment at $973 \mathrm{~K}$ of the acid-treated carbon produces elimination of the oxygen surface complexes, only a fraction of $\mathrm{CO}$ groups with high thermal stability remain. However, the surface area and pore volume increase, due to carbon gasification. After oxidation, activated carbons prepared with steam fixed a larger amount of oxygen groups than carbons activated with carbon dioxide, as a consequence of the wider microporosity created by steam activation. However, carbons activated with $\mathrm{CO}_{2}$ exhibit the high surface area and more stability of oxygen surface groups after heat treatment. Finally, date pits could be used as precursors to produce activated carbons with a well developed porosity and tailored oxygen surface groups for different applications.

\section{References}

1 Rodriguez-Reinoso F, Carbon, 1998, 36(3), 159.

2 Marsh T H and Rodríguez-Reinoso F, Activated Carbon, Elsevier Amsterdam, 2006.

3 Boehm H P, In: Eley D D, Pines H and Weisz P B, Editors, Advances in Catalysis, Vol. 16, New York: Academic Press, 1966, 179-274.

4 Donnet J B, Carbon, 1968, 6, 161-176.

5 Belhachemi M, Rios R V R A, Addoun F, Silvestre-Albero J, Sepulveda-Escribano A and Rodriguez- Reinoso F, J Anal Appl Pyrolysis, 2009,86,168-172.

6 Rodriguez-Reinoso F, Garrido J, Martin-Martinez J M, Molina-Sabio M and Torregrosa R, Carbon, 1989, 27, 23

7 Figueiredo J L, Pereira M F R, Freitas M M A and Orfao J J M, Carbon, 1999, 37(9), 1379-1389.

8 Faria P C C, Orfao J J M and Pareira M F R, Water Res., 2004, 38(8), 2043-2052

9 Rios R V R A, Silvestre-Albero J, Sepulveda-Escribano A and Rodriguez-Reinoso F, Colloids Surf A: Phys Eng Asp., 2007, 300, 180-190.

10 Otake Y and Jenkins R G, Carbon, 1993, 31, 109.

11 Leon Y, Leon C A, Solar J M, Calemma V and Radovic L R, Carbon, 1992, 30, 797-811. 


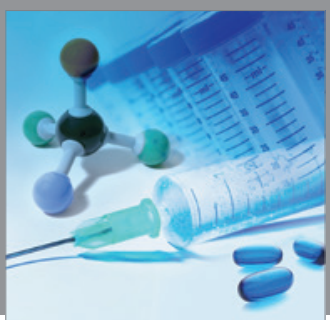

International Journal of

Medicinal Chemistry

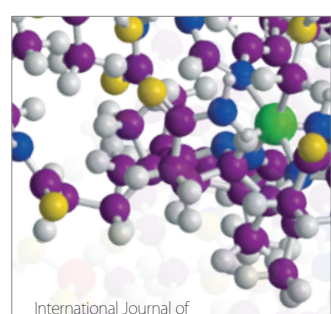

Carbohydrate Chemistry

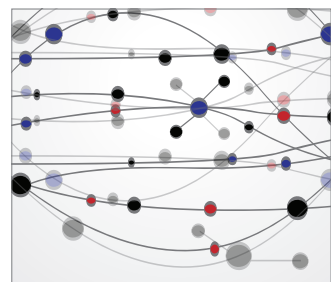

The Scientific World Journal
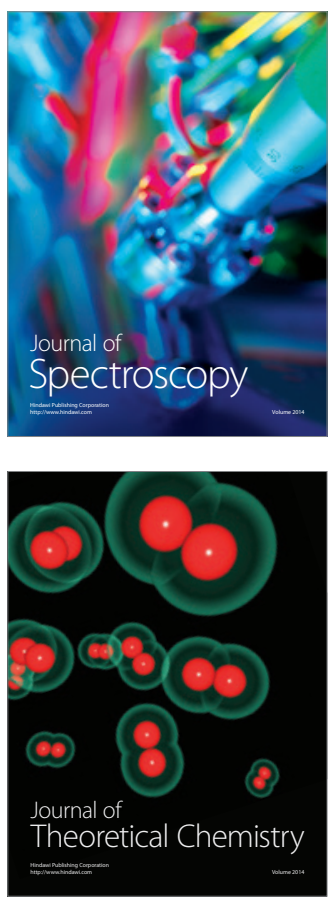
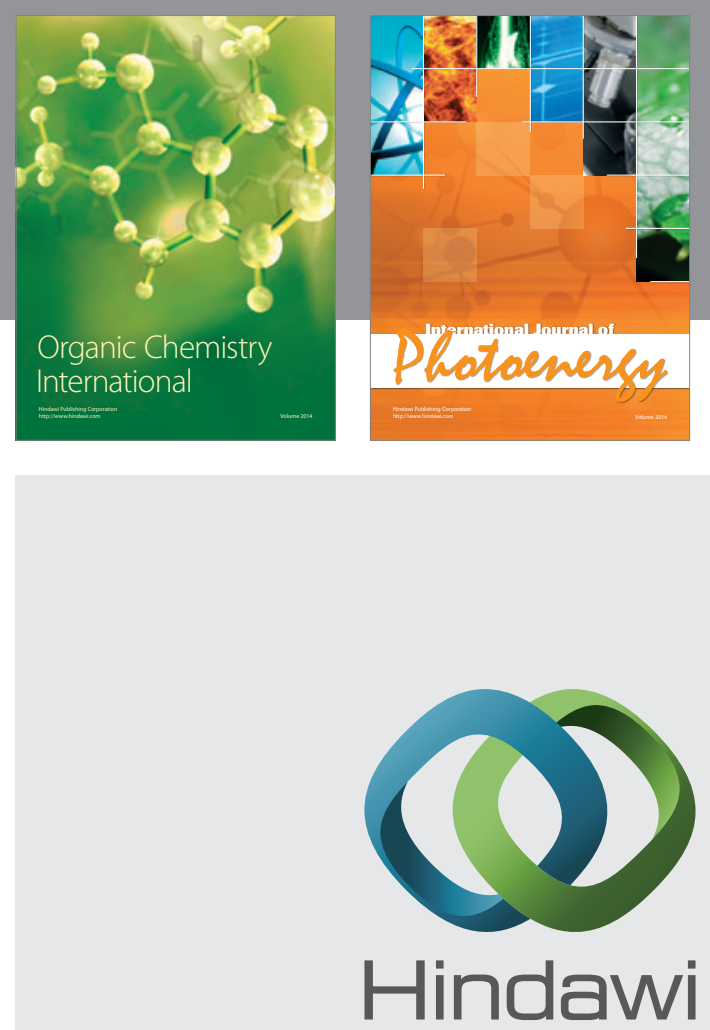

Submit your manuscripts at

http://www.hindawi.com
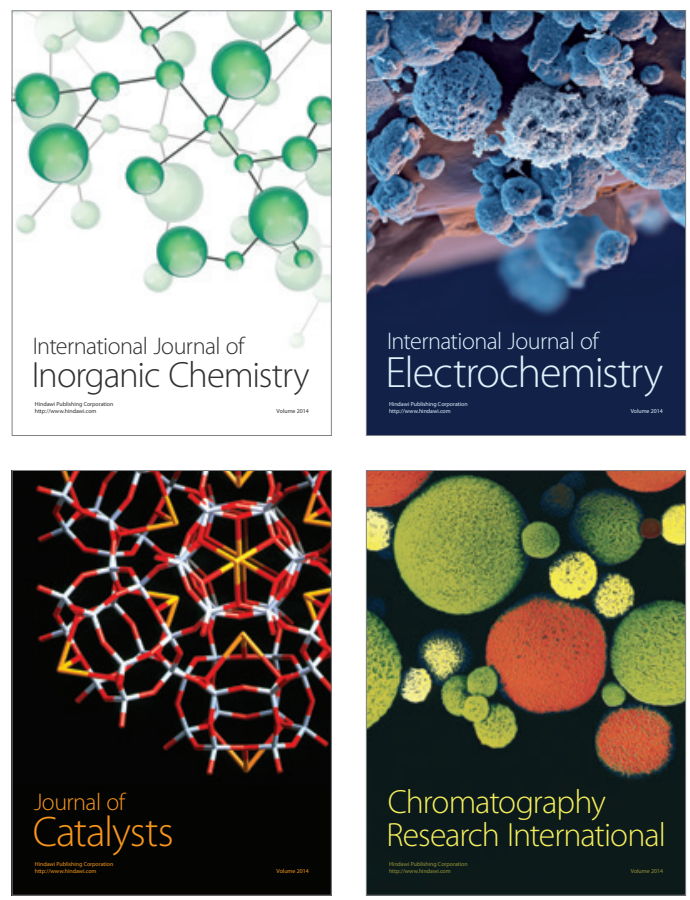
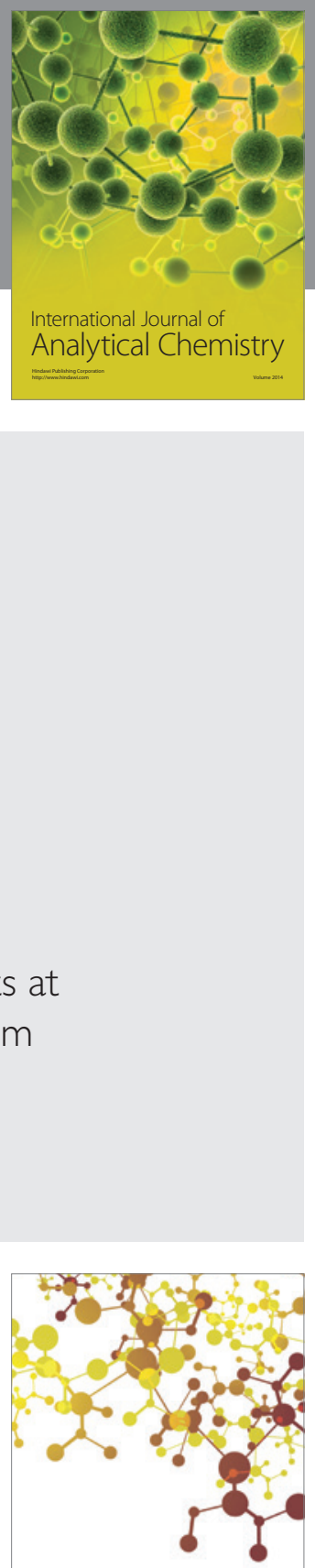

Journal of

Applied Chemistry
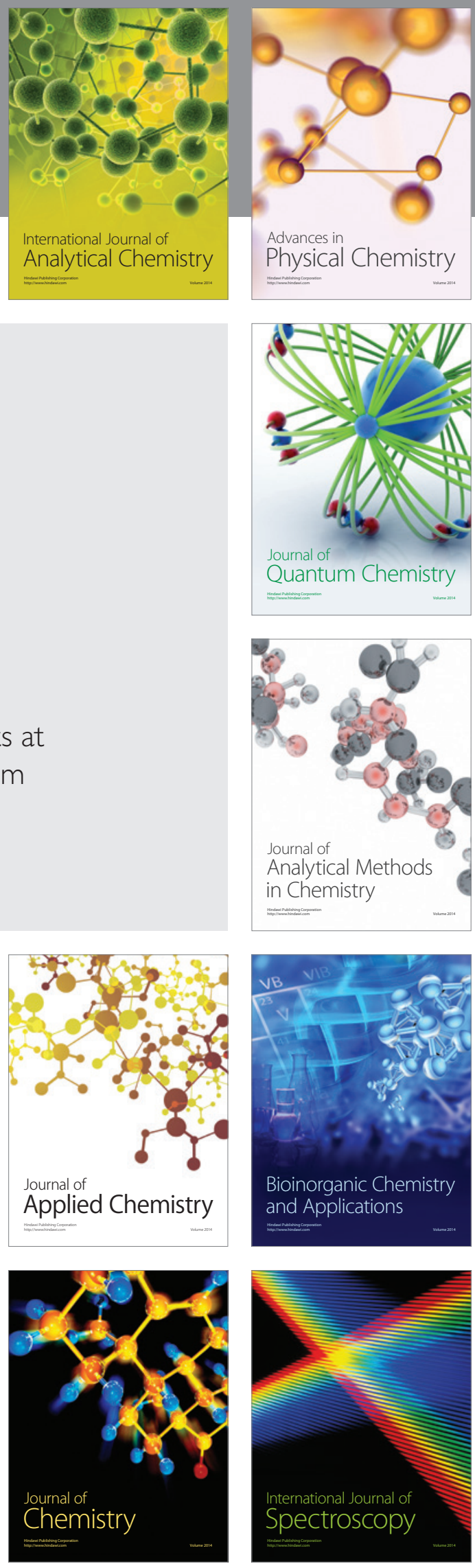